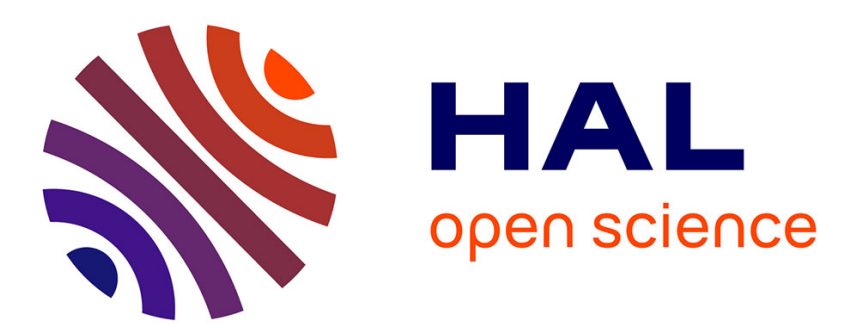

\title{
The current provided by oxygen-reducing microbial cathodes is related to the composition of their bacterial community
}

Mickaël Rimboud, Elie Desmond-Le Quemener, Benjamin Erable, Théodore Bouchez, Alain Bergel

\section{To cite this version:}

Mickaël Rimboud, Elie Desmond-Le Quemener, Benjamin Erable, Théodore Bouchez, Alain Bergel. The current provided by oxygen-reducing microbial cathodes is related to the composition of their bacterial community. Bioelectrochemistry, 2015, vol. 102, pp. 42-49. 10.1016/j.bioelechem.2014.11.006 . hal-01149734

\author{
HAL Id: hal-01149734 \\ https://hal.science/hal-01149734
}

Submitted on 7 May 2015

HAL is a multi-disciplinary open access archive for the deposit and dissemination of scientific research documents, whether they are published or not. The documents may come from teaching and research institutions in France or abroad, or from public or private research centers.
L'archive ouverte pluridisciplinaire HAL, est destinée au dépôt et à la diffusion de documents scientifiques de niveau recherche, publiés ou non, émanant des établissements d'enseignement et de recherche français ou étrangers, des laboratoires publics ou privés. 


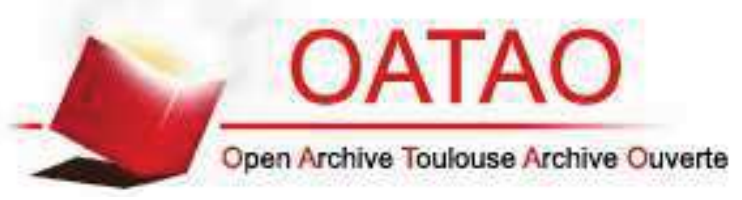

\section{Open Archive TOULOUSE Archive Ouverte (OATAO)}

OATAO is an open access repository that collects the work of Toulouse researchers and makes it freely available over the web where possible.

This is an author-deposited version published in : http://oatao.univ-toulouse.fr/ Eprints ID : 13878

To link to this article : DOI:10.1016/j.bioelechem.2014.11.006 URL : http://dx.doi.org/10.1016/j.bioelechem.2014.11.006

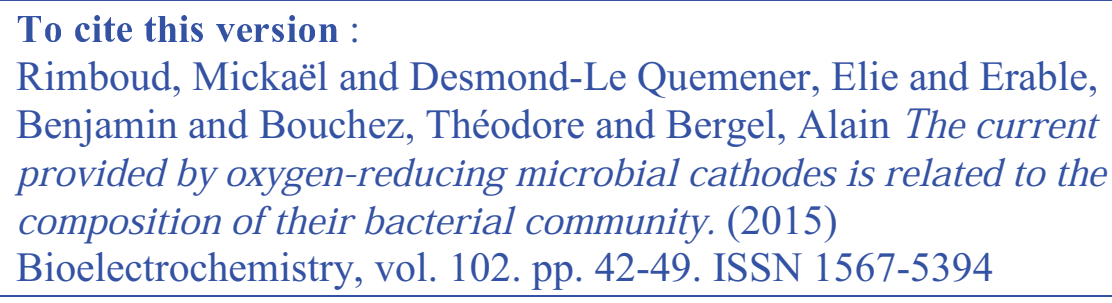

Any correspondance concerning this service should be sent to the repository administrator: staff-oatao@,listes-diff.inp-toulouse.fr 


\title{
The current provided by oxygen-reducing microbial cathodes is related to the composition of their bacterial community
}

\author{
Mickaël Rimboud ${ }^{\mathrm{a}, *}$, Elie Desmond-Le Quemener ${ }^{\mathrm{b}}$, Benjamin Erable ${ }^{\mathrm{a}}$, Théodore Bouchez ${ }^{\mathrm{b}}$, Alain Bergel $^{\mathrm{a}}$ \\ a Laboratoire de Génie Chimique, CNRS, Université de Toulouse, 4 allée Emile Monso, 31432 Toulouse, France \\ ${ }^{\mathrm{b}}$ IRSTEA-Unité de Recherche Hydrosystèmes et Bioprocédés, 1 rue Pierre-Gilles de Gennes, CS 10030, 92761 Antony, France
}

Keywords:

Oxygen reduction

Microbial cathode

Biocathode

Deinococci

Microbial fuel cell

\begin{abstract}
A B S T R A C T
Oxygen reducing biocathodes were formed from sludge under constant polarization at -0.2 and $+0.4 \mathrm{~V} / \mathrm{SCE}$. Under chronoamperometry at $\mathrm{pH} 10.3 \pm 0.3$, current densities of $0.21 \pm 0.03$ and $0.12 \pm 0.01 \mathrm{~A} \mathrm{~m}^{-2}$ were $^{2}$ displayed at $-0.2 \mathrm{~V} / \mathrm{SCE}$ by the biocathodes formed at -0.2 and $0.4 \mathrm{~V} / \mathrm{SCE}$, respectively. Voltammetry revealed similar general characteristics for all biocathodes and higher diffusion-limited current densities $(0.84 \pm$ $0.26 \mathrm{~A} \mathrm{~m}^{-2}$ ) than chronoamperometry. Up to $3.7 \mathrm{~A} \mathrm{~m}^{-2}$ was reached under air bubbling. A theoretical model was proposed to show the consistency of the chronoamperometric and voltammetric data.

The biocathodes formed at $-0.2 \mathrm{~V} / \mathrm{ECS}$ that gave the highest electrochemical performance showed a homogeneous selection of Deinococcus-Thermus and Gemmatimonadetes, while the biocathodes formed at $0.4 \mathrm{~V} / \mathrm{SCE}$ were enriched in different bacteria. The biocathode that led to the worst electrochemical characteristics, while formed at $-0.2 \mathrm{~V} / \mathrm{SCE}$, showed the largest bacterial diversity. The biocathode performance was consequently related to the enrichment in specific microbial phyla. Moreover, the strong presence of bacteria parented to Deinococci may also have some interest in biotechnology.
\end{abstract}

\section{Introduction}

Microbial fuel cells (MFCs) may represent a promising technology to extract electrical energy directly from the chemical energy contained in low cost and widely available organic matters. Amazing advances have been done on fundamental understanding and practical development of microbial anodes, but the low efficiency of oxygen reducing (OR) cathodes still limits MFC performance. Microbial cathodes have been identified as an interesting alternative to the abiotic air-cathodes that are implemented in most MFCs [1]. Such biocathodes have been formed from various natural environments including seawater [2,3], soils [4], sludge and wastewater [5-7]. Aerated sludge and nitrifying biomass have been asserted to be particularly appropriate inocula due to their richness in autotrophic bacteria [8-11].

Despite the various possibilities to form OR microbial cathodes, this research field is still in its infancy and a lot remains to be done to understand the mechanisms and increase the performance. In particular, the factors that may influence the selection of the microorganisms that colonize the electrode surface, or even if a microbial selection occurs or not, remain to be established.

Different works are available in the literature that studied the microbial population of OR biocathodes. They analyzed the microbial diversity by mean of different techniques: DGGE [6], clone library [12-14],

\footnotetext{
* Corresponding author.

E-mail address: mickael.rimboud@ensiacet.fr (M. Rimboud).
}

phylochip [15] and in more recent studies 16S-DNA pyrosequencing [16-18]. However, these studies were realized on biocathodes formed during MFC operation, so that no potential control was applied. As the potential of the cathode conditions the energy recoverable by the bacteria, it may play a crucial role in bacterial selection. To establish the possible impact of the potential on the selection of microorganisms, experiments should be performed using analytical 3-electrode set-ups and potentiostatically controlled conditions [19].

Two studies have been published that used such an electroanalytical system with the aim to link the applied potential to the bacterial selection on OR biocathodes. Vandecandelaere et al. have analyzed biocathodes formed under polarization at $-0.2 \mathrm{~V} / \mathrm{SCE}$ in seawater, using clone libraries [3]. They observed that the bacterial population of the biocathode was similar to the population of the surrounding seawater and concluded to the absence of any bacterial selection on the biocathode. Nevertheless, it should be mentioned that only the cultivable part of the population was addressed in this study. Xia et al. have analyzed the population of OR biocathodes formed under three different potentials, $0.2,0.06$, and $-0.1 \mathrm{~V} / \mathrm{SCE}$, from a mix of aerobic sludge and a previously enriched biocathode consortia [11]. They observed higher proportions of Bacteroidetes and Thiorhodospira sp. as the potential decreased, showing a clear impact of the applied potential on the bacterial selection. Eventually, these studies presented only one population analysis for each of experimental condition, while microbial electrochemical systems are known for their considerable versatility [20]. Further studies are 
consequently required to clearly establish the impact, or not, of the polarization potential on the selection of bacteria on OR biocathodes.

The objective of the present work was to investigate whether a bacterial selection occurred when an OR biocathode is formed from a complex inoculum and how it could impact the performance of the biocathode. Biocathodes were formed in a synthetic medium inoculated by longterm aerated sludge, using two distant polarization potential, -0.2 and $+0.4 \mathrm{~V} / \mathrm{SCE}$. The first potential has already been identified as producing high performance OR biocathodes [7,10,11] and so consequent current densities were expected. The second one was chosen due to its closeness to the standard potential for oxygen reduction at $\mathrm{pH} 10$. At this potential, no current production was expected from the electrode. These two values of potential represent two very different situations, which could affect the biocathode formation. Replicates were realized for each experimental condition: four electrodes were formed at $-0.2 \mathrm{~V} / \mathrm{SCE}$, two electrodes were formed at $+0.4 \mathrm{~V} / \mathrm{SCE}$. The biocathodes were electrochemically characterized by chronoamperometry and cyclic voltammetry and the communities present in each biofilm were identified by 16S-DNA pyrosequencing. The replicates used here showed that the applied potential had a clear impact on the bacterial communities of oxygen-reducing biocathodes, although it did not allow fully controlling them. The electrochemical performance was linked to the enrichment in specific microbial phyla that can happen at $-0.2 \mathrm{~V} / \mathrm{SCE}$, while the biocathode that exhibited the lowest performance, while formed at the same potential, showed deficient microbial selection.

\section{Materials and methods}

\subsection{Electrochemical setup and tests}

Each electrochemical cell was a three-electrode set-up in a twocompartment $\mathrm{H}$-cell equipped with an anion exchange membrane (Fumasep ${ }^{\circledR}$ FAA-PK, Germany) of $7.1 \mathrm{~cm}^{2}$ surface area (Scheme 1). The working electrode was a $2 \mathrm{~cm}^{2}$ of carbon cloth (Paxitech ${ }^{\circledR}$, France) connected by a platinum wire, the counter-electrode was a $10 \mathrm{~cm}^{2}$ platinum grid and the reference electrode was a saturated calomel electrode (SCE, potential $+0.241 \mathrm{~V} / \mathrm{SHE}$ ). Four holes were drilled in the cap that covered each electrochemical compartment; they were used to introduce the electrodes and the tubes for air or nitrogen bubbling. When the electrochemical cell was air-opened one of these apertures on the anodic and cathodic compartments was not sealed during the experiments. Aerated sludge was collected at a sewage treatment plant (Evry, France) just before the nitrifying step. Its initial $\mathrm{pH}$ was 7.0. A nitrification medium was consequently chosen, which contained a high concentration of ammonium ions. The anolyte was composed as follow: $1.908 \mathrm{~g} \mathrm{~L}^{-1} \mathrm{NH}_{4} \mathrm{Cl}, 0.7 \mathrm{~g} \mathrm{~L}^{-1}$ $\mathrm{K}_{2} \mathrm{HPO}_{4}, 0.7 \mathrm{~g} \mathrm{~L}^{-1} \mathrm{Na}_{2} \mathrm{HPO}_{4}, 28.6 \mathrm{~g} \mathrm{~L}^{-1} \mathrm{KHCO}_{3}$ and $0.5 \mathrm{~mL} \mathrm{~L}^{-1}$ of a mineral solution [21]. The final $\mathrm{pH}$ was adjusted at 7.8 with $\mathrm{HCl} 37 \%$. The catholyte was same medium inoculated with $10 \%$ (v/v) aerated sludges (500 mL final volume). Each compartment was air-opened without stirring.

The pH was daily measured in each compartment but not controlled. Two reactors without electrodes were used as control experiments. When indicated, nitrogen or air bubbling was punctually performed into the catholyte. All experiments were conducted in a stove thermostated at $40{ }^{\circ} \mathrm{C}$. This temperature was chosen to favor fast high bacterial growth, even if it lowered the concentration of dissolved oxygen in the medium $\left(0.41 \mathrm{mM}\right.$ against $0.52 \mathrm{mM}$ at $\left.25^{\circ} \mathrm{C}\right)$.

Microbial cathodes were formed under constant polarization (chronoamperometry) using a multichannel potentiostat (Biologic, France, EC-Lab software). Four electrodes (numbered 1 to 4) were polarized at $-0.2 \mathrm{~V} / \mathrm{SCE}$, two electrodes (numbered 5 and 6 ) at $+0.4 \mathrm{~V} /$ SCE. At some times the chronoamperometry was interrupted and cyclic voltammetry was recorded at $1 \mathrm{mV} \mathrm{s}^{-1}$, starting at the polarization potential and scanning to $0.3 \mathrm{~V}$ (upper limit for the electrodes polarized at $-0.2 \mathrm{~V} / \mathrm{SCE}$ ) or $0.5 \mathrm{~V}$ (for the electrodes polarized at $+0.4 \mathrm{~V} / \mathrm{SCE}$ ) and back down to $-0.6 \mathrm{~V} / \mathrm{SCE}$. Three voltammograms were successively recorded each time, only the second was reported here for the sake of simplicity. The current densities discussed in the text were average values calculated for each group of electrodes formed at the same potential.

\subsection{Bacterial community analysis}

The bacterial populations of the cathodic biofilms were analyzed using $16 \mathrm{~S}$ rDNA-pyrotags sequencing. DNA was extracted with reagent kit MOBIO PowerSoil ${ }^{\circledR}$ DNA Isolation. The DNA extraction was quantified by fluorometry (QuBit ${ }^{\mathrm{TM}}$ fluorometer with Quant-it ${ }^{\mathrm{TM}}$ assay kit, Invitrogen) and spectrophotometry (WPA Biowave ${ }^{\mathrm{TM}} \mathrm{II}$ ) which also permitted to check DNA quality thanks to the ratio of UV absorbance at $260 / 280 \mathrm{~nm}$ and 260/230 nm. DNA samples were finally sent to Research and Testing Laboratory (RTL - Texas, USA) where 454 pyrosequencing (Roche) with $28 \mathrm{~F}$ ( $5^{\prime}$ - GAG TTT GAT YMT GGC TC $-3^{\prime}$ ) and 519R (5'- GWA TTA CCG CGG CKG CTG -3') primers was performed.

Resulting data were analyzed with the open source software package QIIME “Quantitative Insights Into Microbial Ecology" [22]: 16S DNA sequence quality was controlled using a sliding window $50 \mathrm{nt}$ long requiring an average quality above 25 . The sequences were thus trimmed to the end of the last window with required average quality and discarded if their final length was less than $150 \mathrm{nt}$. In addition, remaining reads where the longest homopolymer was greater than $6 \mathrm{nt}$ or containing an ambiguous base were also discarded. Sequences were then aligned with PyNAST [23] using the Silva 108 database corealigned set formatted for QIIME as a template [24]. Putative chimeric sequences were identified with ChimeraSlayer and removed from dataset [25]. Remaining sequences were clustered in operational taxonomic

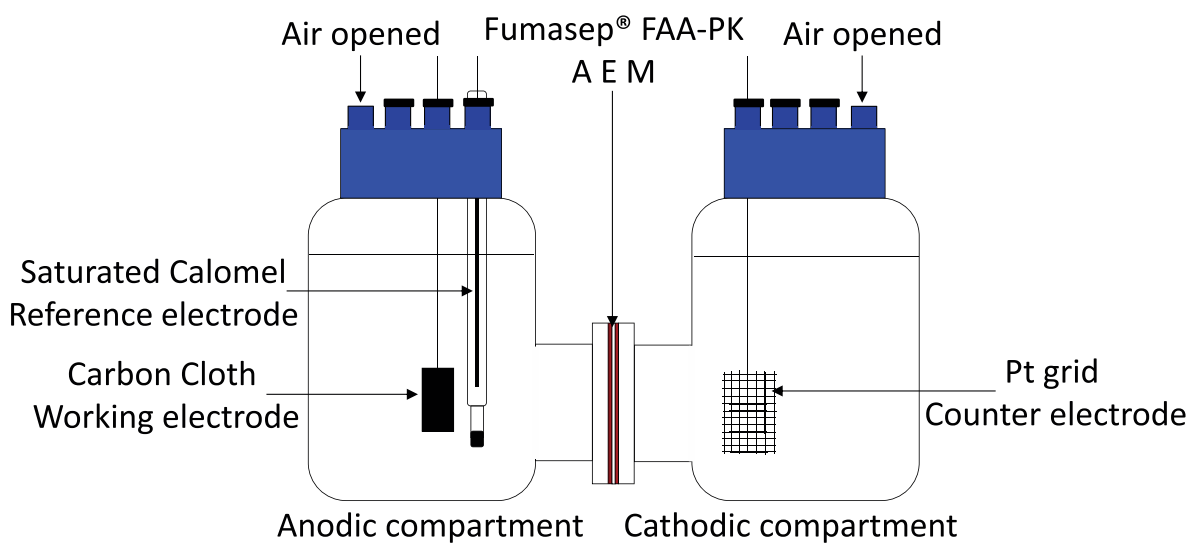

Scheme 1. Experimental set-up. 
units (OTUs) at 97\% sequence similarity using uclust [26]. OTUs taxonomic assignment was then performed with the RDP classifier [27], a 0.8 bootstrap cut-off using the most abundant sequence in each OTU as representative sequence. Finally OTUs identified as Archaea or Eukarya were discarded.

DPCoA analysis was performed using R package phyloseq [28] on OTUs with coverage of at least 10 , using relative abundances and a phylogenetic tree computed using FastTree [29].

For deeper phylogenetic analysis, representative sequences of OTUs affiliated to Deinococci where introduced in the ARB software to check the quality of alignments and of the taxonomic assignation [30]. Sequences of representative species of the current known diversity of the phylum Deinococcus-Thermus together with sequences of uncultured bacteria close to our sequences were then exported for deeper phylogenetic analysis. Three $\alpha$-Proteobacterial sequences were also exported as an outgroup. Exported sequences were aligned with PyNAST as stated above. Unambiguously aligned positions were extracted from the alignment using the BMGE program with block size of one and allowing 40\% gaps in columns [31]. The maximum likelihood tree was then inferred with PhyML using the GTR model with optimized equilibrium frequencies, a gamma correction to take into account the heterogeneity of evolutionary rates across sites (four discrete classes of sites, an estimated alpha parameter and an estimated proportion of invariable sites) and SPR \& NNI topology searches with five random starting trees [32]. The robustness of each branch was estimated by the non-parametric bootstrap procedure implemented in PHYML (100 replicates of the original data set and the same parameters). The phylogenetic tree was edited and exported using FigTree (http://tree.bio.ed. ac.uk/software/figtree/).

\section{Results and discussion}

\subsection{Electrochemical characterization of the biocathodes}

\subsubsection{Chronoamperometries}

The four cathodes formed at $-0.2 \mathrm{~V} / \mathrm{SCE}$ showed identical current variation with time illustrated in Fig. $1 \mathrm{~A}$.

A reduction current appeared after an initial lag time around 2 days and reached a plateau after around 6 days. Various stresses were imposed to the electrodes: nitrogen bubbling, air bubbling, 1-day polarization interruption (days 9.3 to 10.5) and water additions to compensate evaporation (at days 3.7 and 10.5). In each case, after the end of the stress the electrodes recovered the current they provided under "standard" conditions, i.e. constant polarization in quiescent solution without any gas flow. This behavior showed a remarkable stability of the electrode performance, which supplied under "standard" condition $0.21 \pm 0.03 \mathrm{~A} \mathrm{~m}^{-2}$ (average of the four bioanodes). The nitrogen flux established on day 7.5 rapidly annihilated the reduction current and current started again immediately after stopping the nitrogen sparge. It confirmed that the current observed was indeed due to oxygen reduction (OR). Air bubbling was applied from day 15.5 to the end of experiment on day 17.4. It increased the reduction current density up to $0.87 \mathrm{~A} \mathrm{~m}^{-2}$ and then slowly stabilized at lower values around $0.36 \mathrm{~A} \mathrm{~m}^{-2}$.

The biocathodes formed at $0.4 \mathrm{~V} / \mathrm{SCE}$ (Fig. 2) initially produced a very low oxidation current density from day 0 to day 9 , probably due to the presence of some soluble substances coming from the inoculum, which were oxidized.

As expected when choosing a quite oxidative polarization potential, no current was then observed from day 10 up to day 62.6. An electroactive biofilm was nevertheless formed during this time, as a switch of the polarization to $-0.2 \mathrm{~V} / \mathrm{SCE}$ on day 62.6 instantly provoked an abrupt drop of current density. The average stable current density obtained after three days of polarization at $-0.2 \mathrm{~V} / \mathrm{SCE}$ was $0.12 \pm$ $0.01 \mathrm{~A} \mathrm{~m}^{-2}$, i.e. significantly smaller than that provided by the biocathodes that were formed at $-0.2 \mathrm{~V} / \mathrm{SCE}$ from the beginning. The biocathodes formed at $+0.4 \mathrm{~V} / \mathrm{SCE}$ did not reduce oxygen at this
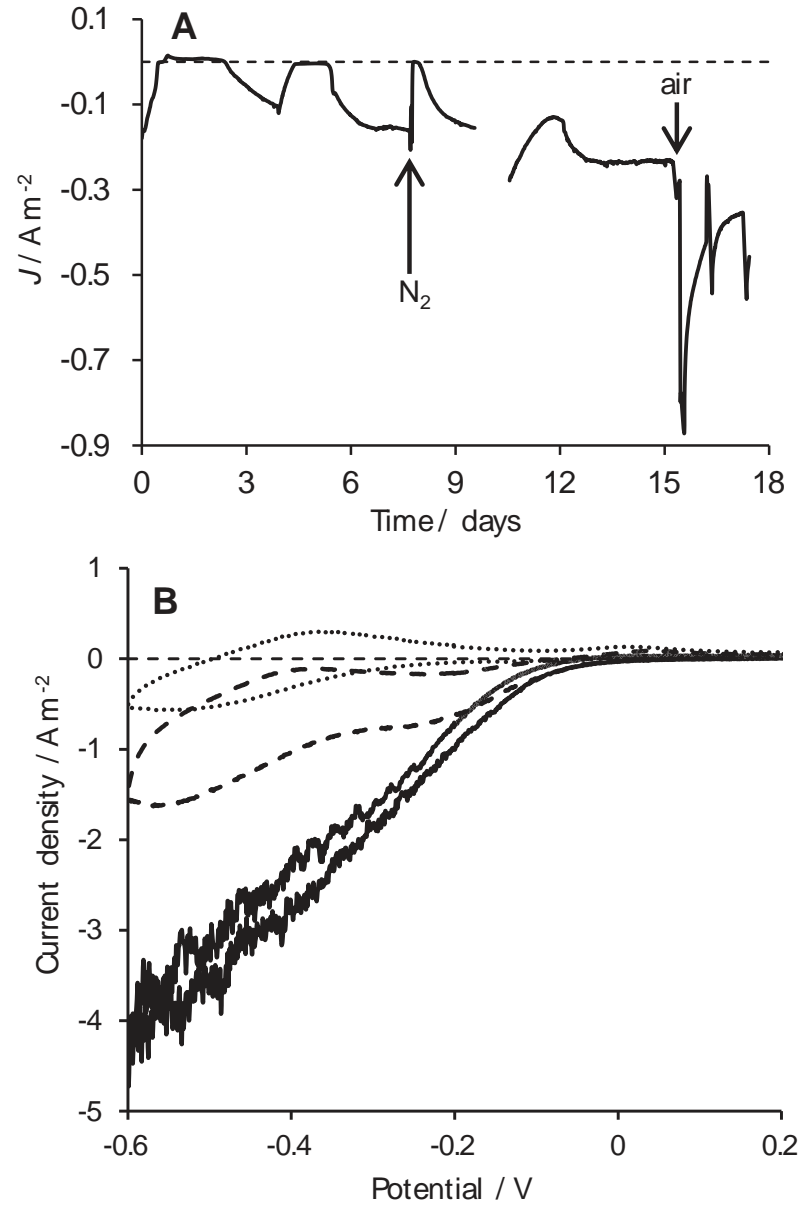

Fig. 1. Electrochemical characterization of a biocathode formed from sludge at $-0.2 \mathrm{~V} / \mathrm{SCE}$ (cathode from reactor 3 in Table 1). A: chronoamperometry: The current increases between days 3.7 and 5.1 and between days 10.5 and 11.8 were due to water addition to compensate evaporation and keep the medium volume constant; B: Cyclic voltammograms of the biocathode under three different conditions: "standard" condition (dashed line), with $\mathrm{N}_{2}$ bubbling (dotted line), with air bubbling (plain line).

potential but they were able to do it as soon as the potential was switched to $-0.2 \mathrm{~V} / \mathrm{SCE}$. Nevertheless, they were less efficient than the biocathodes formed initially at $-0.2 \mathrm{~V} / \mathrm{SCE}$. These results were consistent with previous studies that also observed a clear effect of the applied potential on the biocathode performance $[7,10,11]$.

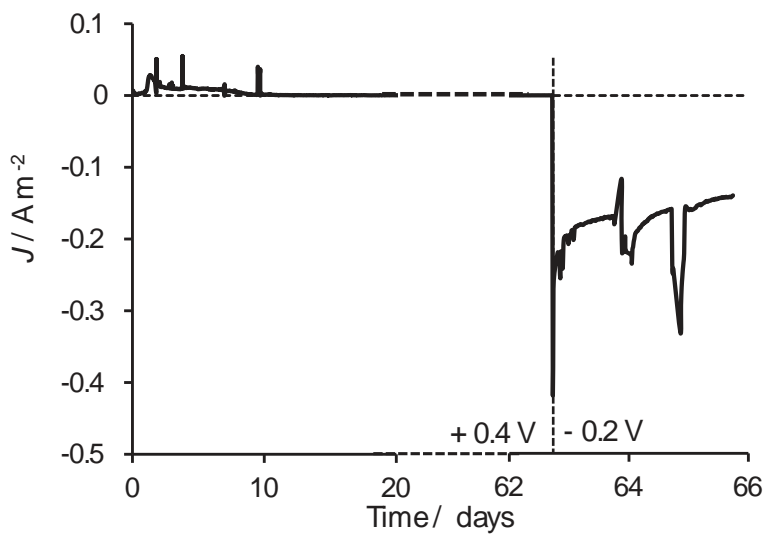

Fig. 2. Chronoamperometry of a biocathode formed from sludge at $0.4 \mathrm{~V} / \mathrm{SCE}$. The applied potential was switched to $-0.2 \mathrm{~V} / \mathrm{SCE}$ on day 63 . 
The pHs of both anodic and cathodic compartments were daily measured. In the cathodic compartments, a fast alkalinization occurred from the starting value of 7.8 to around 9.5 in the first five days. A slower growth was then observed up to $10.3 \pm 0.3$ at the end of experiments. A similar evolution was observed in the anodic compartments, though the values remained lower by around $0.3 \mathrm{pH}$ unit than on the cathodic side. An identical pH change was observed with the two control reactors carried out in exactly the same conditions but without electrodes, which meant that pH change was not provoked by the electrochemical processes but by the metabolic activity of the planktonic microorganisms. Similar spontaneous $\mathrm{pH}$ drift, which was not linked to the electrochemical reactions, has already been reported in microbial electrochemical systems that implemented environmental inocula in non-buffered conditions. For instance, $\mathrm{pH}$ change from 7.4 to 8.6 has been observed with garden compost leachate [33] and a shift from 7.0 to 9.6 with raw paper mill effluents [34]. Here, the final stabilization around $\mathrm{pH} 10$ was consistent with the buffer effect of the $\mathrm{HCO}_{3}^{-}$ions in the synthetic medium. Under these slightly alkaline conditions, the electrode reactions were:

$\mathrm{O}_{2}+2 \mathrm{H}_{2} \mathrm{O}+4 \mathrm{e}^{-} \rightarrow 4 \mathrm{OH}^{-}$

on the cathode and:

$2 \mathrm{H}_{2} \mathrm{O} \rightarrow \mathrm{O}_{2}+4 \mathrm{H}^{+}+4 \mathrm{e}^{-}$

on the platinum anode (auxiliary electrode). Hydroxide ions are generated on the cathode and proton on the anode, which explains the $\mathrm{pH}$ gradient between the two compartments. The $\mathrm{pH}$ evolution was also consistent with the direction of ionic migration of carbonates and hydrogenocarbonates through the anion exchange membrane [35].

Oxygen reduction (Eq (1)) is disadvantaged by alkaline $\mathrm{pH}$ and favored in acidic solution as already observed experimentally [8]. Using activated sludge as inoculum in a phosphate buffer solution Strik et al. have observed a decrease of the current density from -0.66 to -0.13 $\mathrm{A} \mathrm{m}^{-2}$ as pH grew from 5 to 9 . In comparison, current densities recorded here $\left(0.21 \pm 0.03\right.$ or $0.12 \pm 0.01 \mathrm{~A} \mathrm{~m}^{-2}$ with the biocathodes formed at -0.2 and $0.4 \mathrm{~V} / \mathrm{SCE}$, respectively) were pretty high at $\mathrm{pH}$ as high as $10.3 \pm 0.3$. The non-controlled $\mathrm{pH}$ may lead to the progressive selection of alkaliphile species able to efficiently reduce oxygen at high $\mathrm{pH}$.

\subsubsection{Cyclic voltammetries}

Cyclic voltammograms ( $\mathrm{CV}$ ) were recorded corresponding to the three different situations: in "standard" conditions, i.e. in quiescent solution without gas feeding, under nitrogen bubbling and under air bubbling (Fig. 1B). The biocathodes formed at -0.2 and $0.4 \mathrm{~V} / \mathrm{SCE}$ gave similar CV, as can be seen in Table 1 which reports CV characteristics for each electrode.

Under "standard" conditions oxygen reduction started around -0.0 $\mathrm{V} / \mathrm{SCE}$ with an apparent half-wave potential of $-0.16 \mathrm{~V} / \mathrm{SCE}$. It was a low potential to observe OR compared to previous works realized with aerated or nitrifying sludge $[8,10]$. The high $\mathrm{pH}$ value that the medium progressively got here partially explains the shift towards low potential. The Nernst equation for OR in alkaline medium (Eq. (2)) is:

$\mathrm{E}=\mathrm{E}^{0}+\frac{\mathrm{RT}}{4 \mathrm{~F}} \ln \frac{\mathrm{a}_{\mathrm{OH}}^{4}}{\mathrm{a}_{\mathrm{O}_{2}}}$

where $\mathrm{E}^{0}=0.401 \mathrm{~V} / \mathrm{SHE}$ is the standard potential for oxygen reduction, $\mathrm{R}$ the universal gas constant $\left(8.314 \mathrm{~J} \mathrm{~mol}^{-1} \mathrm{~K}^{-1}\right), \mathrm{T}$ the temperature $(\mathrm{K})$, $\mathrm{F}$ the Faraday constant $\left(96,485 \mathrm{C} \mathrm{mol}^{-1}\right)$ and $\mathrm{a}_{\mathrm{OH}^{-}}$and $\mathrm{a}_{\mathrm{O}_{2}}$ the respective activity of hydroxide ions and dissolved oxygen. At $40{ }^{\circ} \mathrm{C}$, $\mathrm{a}_{\mathrm{O}_{2}}$ is $0.41 \times 10^{-3} \mathrm{M}$ and Eq. (3) gives:

$\mathrm{E}=\mathrm{E}^{0}+0.815-0.062 \mathrm{pH}$.

The potential decreases of $62 \mathrm{mV}$ per $\mathrm{pH}$ unit. The formal potential of $\mathrm{OR}$ at $\mathrm{pH} 10$ was $-0.170 \mathrm{~V} / \mathrm{SCE}(186 \mathrm{mV}$ lower than at $\mathrm{pH} 7.0)$. The formal potential at $\mathrm{pH} 10$ was not low enough to fully explain the shift towards negative potentials that was observed here in comparison to other works realized with similar inoculum at neutral [10] or slightly acid $\mathrm{pH}[8]$. A part of the negative potential shift must be imputed to the intrinsic properties of the microbial communities. The main difference with respect to the previous studies was the absence of $\mathrm{pH}$ control in the present experiments. Letting the $\mathrm{pH}$ derive may result in the selection of species that are able to generate high current densities at alkaline $\mathrm{pH}(10.3 \pm 0.3)$, however it contributed to lower the potential at which OR was observed.

The voltammograms recorded in standard condition (Fig. 1B) displayed a plateau of limited current since around $-0.25 \mathrm{~V} / \mathrm{SCE}$ before a second reduction signal appeared at potentials lower than $-0.35 \mathrm{~V} /$ SCE (reductive scan). When air was brought into the cell, the voltammograms displayed a considerably enhanced signal for oxygen reduction. A continuously increasing current was observed since $-0.1 \mathrm{~V} / \mathrm{SCE}$ without any plateau. The plateau observed under standard conditions was consequently clearly due to oxygen mass transfer limitation.

In the absence of dissolved oxygen (nitrogen bubbling) no current was observed corresponding to $\mathrm{OR}$. The second signal reduction remained below $-0.3 \mathrm{~V} / \mathrm{SCE}$ but with lower current densities than in the presence of oxygen. An oxidation current was observed on the backwards (oxidative) scan. A redox compound was present in the biofilm, which was reduced and oxidized in a zone of low potentials.

Characteristics of the CV displayed by the different biocathodes are compiled in Table 1. For each electrode, three different values of current density were considered: the current density at $-0.2 \mathrm{~V} / \mathrm{SCE}$ measured on the reductive scan $\left(J_{-0.2 \mathrm{~V}}\right)$, the diffusion-limited current densities displayed under "standard" conditions measured on the reductive scan $\left(J_{\text {lim }}\right)$ and the current density displayed under air bubbling at the arbitrarily chosen potential of $-0.4 \mathrm{~V} / \mathrm{SCE}\left(J_{\text {air }}\right)$ determined from the reductive scan. As a whole, biocathodes differed when considering performances displayed at fixed potential $\left(J_{-0.2 \mathrm{~V}}, J_{\text {air }}\right)$ but exhibited similar characteristics when considering values of $J_{\text {lim }}$, except the electrode number 1 , which stood out from the others by displaying significantly lower values for each parameter $\left(J_{\text {lim }}=-0.15 \mathrm{~A} \mathrm{~m}^{-2}\right)$. Such experimental deviation has been observed in other works on microbial electrodes and justifies the systematic use of replicates in the domain of microbial electrochemistry [19]. The other three electrodes formed at

\section{Table 1}

Characterization of biocathodes 1 to 3: Chronoamperometric and voltammetric experimental results and diversity indexes for each electrode. The current densities discussed in the text were average values calculated from these raw data for each group of electrodes.

\begin{tabular}{|c|c|c|c|c|c|c|c|c|c|}
\hline \multirow[t]{2}{*}{ Electrode number } & \multirow[t]{2}{*}{ Polarization potential (V/SCE) } & \multirow{2}{*}{$\frac{C A}{J_{C A}\left(\mathrm{~A} \mathrm{~m}^{-2}\right)}$} & \multicolumn{3}{|c|}{ Cyclic voltammetry (CV) } & \multirow[t]{2}{*}{ Number of OTUs } & \multirow[t]{2}{*}{ Chao1 } & \multirow[t]{2}{*}{ Shannon } & \multirow[t]{2}{*}{ Simpson } \\
\hline & & & $J_{-0.2 \mathrm{~V}}\left(\mathrm{~A} \mathrm{~m}^{-2}\right)$ & $J_{\text {lim }}\left(\mathrm{A} \mathrm{m}^{-2}\right)$ & $J_{-0.4 \mathrm{~V}, \text { air }}\left(\mathrm{A} \mathrm{m}^{-2}\right)$ & & & & \\
\hline 1 & -0.2 & -0.20 & -0.07 & -0.15 & -0.45 & 329 & 413 & 6.54 & 0.97 \\
\hline 2 & & -0.19 & -0.53 & -0.65 & -2.0 & 181 & 297 & 4.99 & 0.92 \\
\hline 3 & & -0.24 & -0.63 & -1.1 & -3.7 & 220 & 276 & 5.95 & 0.96 \\
\hline 4 & & -0.22 & -0.60 & -0.77 & -2.7 & 239 & 309 & 6.44 & 0.97 \\
\hline 5 & 0.4 then -0.2 at day 63 & -0.09 & -0.46 & -0.64 & -2.1 & 162 & 190 & 6.13 & 0.97 \\
\hline 6 & & -0.17 & -0.28 & -0.63 & - & 227 & 261 & 5.39 & 0.92 \\
\hline
\end{tabular}


$-0.2 \mathrm{~V} / \mathrm{SCE}$ (numbers 2, 3 and 4 ) gave homogeneous performance $\left(J_{\text {lim }}=-0.84 \pm 0.26 \mathrm{~A} \mathrm{~m}^{-2}\right.$ ) and the cathodes formed at $0.4 \mathrm{~V} / \mathrm{ECS}$ led to parameters of the same order of magnitude $\left(J_{\text {lim }}=-0.63 \pm\right.$ $0.01 \mathrm{~A} \mathrm{~m}^{-2}$ ). The clear difference that was observed on the current densities displayed during chronoamperometry faded away when considering the voltammetric parameter $J_{\text {lim }}$. As a whole, and except the particular case of electrode $1, J_{\text {lim }}$ values revealed that all biocathodes displayed similar characteristics, comparable to those observed with similar inocula in previous works. Maximum diffusion-limited current densities of $-1.1 \mathrm{~A} \mathrm{~m}^{-2}\left(\mathrm{Jlim}_{\mathrm{lim}}\right)$ were obtained here and up to $-3.7 \mathrm{~A} \mathrm{~m}^{-2}\left(J_{\text {air }}\right)$ under air flux. The highest performance reported in literature is of $-4 \mathrm{~A} \mathrm{~m}^{-2}$ with air forced into the cell [5].

\subsubsection{Preliminary basis for a theoretical model}

The shape of the CVs recorded in standard condition (Fig. 1B, dashed line) presents reproducible deviations from the conventional CV that may be expected from a simple electrochemical system, which deserve some comments. The current densities measured on the CV at $-0.2 \mathrm{~V} /$ SCE $\left(J_{-0.2 \mathrm{~V}}\right)$ were significantly higher than those recorded during chronoamperometry, while potentials were identical. So a large difference would not be observed with conventional cathodes because the low scan rate of $1 \mathrm{mV} \mathrm{s}^{-1}$ used for CV ensured stationary state or close to stationary state conditions, at which voltammetry and chronoamperometry would give similar current densities at identical potential. Furthermore, a significant hysteresis was observed in the zone of low potentials between the forward (reductive) and backward (oxidative) scans. This hysteresis was not related to a capacitive phenomenon. A capacitive phenomenon would induce a constant capacitive current on the whole scanned potential range. Here, the hysteresis was clearly observed at potentials lower than $-0.1 \mathrm{~V} / \mathrm{SCE}$, while it did not occur above $0.0 \mathrm{~V} / \mathrm{SCE}$. Such a hysteresis that appeared only in one part of the voltammogram cannot be attributed to a capacitive effect.

The voltammetric behavior of the biocathodes can be quantitatively explained on the basis of a biofilm scheme organized into two parts: the electrode surface vicinity and the remaining biofilm volume. The layer close to the electrode surface ensures efficient catalysis of OR via adsorbed extracellular proteins for example or any other mechanisms that can be contemplated. The volume of the biofilm that is not in the vicinity of the electrode surface contains redox compounds that undergo electron transfer with the electrode:

$\mathrm{Ox}+\mathrm{ne}-\underset{k_{\text {ox }}}{\stackrel{k_{\text {red }}}{\rightleftarrows}}$ Red

and the reaction of the Red form with oxygen regenerates the oxidized form:

$\mathrm{O}_{2}+2 \mathrm{H}_{2} \mathrm{O}+4 / \mathrm{n}$ Red $\stackrel{k}{\rightarrow} \mathrm{OH}^{-}+4 / \mathrm{nOx}$

where $\mathrm{n}$ is the number of electron exchanged by the redox compound. "Ox/Red" is here a generic notation that can represent a single redox compound or a whole set of various compounds entrapped inside the biofilm. We do not make any assumption about the nature of these compounds, which can be extracellular molecules or even microbial cells able to ensure electron transfer with the electrode, whatever may be the possible pathway. Only two basic hypotheses were done: firstly, the electron transport in the biofilm was assumed to be slow between the electrode surface and the redox compound located far from the electrode surface; secondly, re-oxidation of the redox compound by oxygen (Eq. (6)) was fast.

When the CV started, at the beginning of the reductive scan, the biocathode was initially in fully oxidized state. The redox compounds were in oxidized form and oxygen can consequently deeply penetrate into the biofilm without reacting. A large flow of oxygen reached the electrode surface, where it was efficiently reduced thanks to the catalytic mechanisms (Scheme 2A).

The reductive scan gave consequently high currents. During the last part of the reductive scan, the whole set of redox compounds was reduced at the lowest potentials, generating the reductive currents that superimposed to the diffusion-limited current.

At the lower limit, when the potential scan was reversed to the positive direction (beginning of the oxidative scan) the biofilm was in reduced state. Oxygen encountered reduced species (Red) and reacted with them as soon as it started to penetrate into the biofilm. A large part of oxygen was consequently consumed before reaching the electrode surface and its flow at the electrode surface was low (Scheme 2B). Low currents were consequently generated. According to the model, the large difference of the $J_{\text {lim }}$ values recorded on the reductive and oxidative scans was explained by the difference of the oxygen concentration gradients at the electrode surface.

During chronoamperometries, the biocathodes were mainly in reduced state (Scheme 2B), while they were in oxidized state (Scheme 2A) during the reductive scan of CV. The reductive scan of the CVs consequently produced higher currents at $-0.2 \mathrm{~V} / \mathrm{SCE}$ than chronoamperometry at the same potential. The experimental difference observed at the same potential between chronoamperometry and CV is consistent with this qualitative model.

During chronoamperometry, when polarization at $-0.2 \mathrm{~V} / \mathrm{SCE}$ was resumed after one day of interruption (days 9.3 to 10.5 in Fig. 1A) the current density immediately got a high reduction value and then slowly went back to the lower stationary value. During the polarization interruption, the redox compounds were oxidized by oxygen. When the potential was restored at $-0.2 \mathrm{~V} / \mathrm{SCE}$, the redox compounds were reduced, which generated the reduction current that added to the current of oxygen reduction. The part of the current due to reduction of the redox compounds of the biofilm then vanished slowly because this reduction was slow at $-0.2 \mathrm{~V} / \mathrm{SCE}$. It took approximately 1 day to go back to the stationary value. This was the time necessary for the biocathode to shift from the oxidized state (Scheme $2 \mathrm{~A}$ ) to the reduced state (Scheme 2B) under polarization at $-0.2 \mathrm{~V} / \mathrm{SCE}$.

Under nitrogen bubbling, any current due to the presence of oxygen disappeared and only the oxidation and reduction of the redox compound molecules was observed at low potential values. The small oxidation current that lasted in the zone of high potentials confirmed the slow electron transfer between electrode and the redox compounds contained in the biofilm volume. Under air bubbling, the flow of oxygen was considerably increased. The whole set of redox compounds was consequently always oxidized by the high flow of oxygen (Eq. (6)). The current densities were high and were similar for both potential scans, because the redox compounds were maintained in their oxidized state by the high oxygen flow (Scheme 2A).

\subsection{Bacterial community analysis}

A total number of 17,642 pyrotags from the variable region V1-3 of bacterial $16 \mathrm{~S}$ were extracted from all cathodic biofilm samples. After trimming, sorting, and quality control, $68 \%$ of these sequences (12001), with an average read length of $342 \mathrm{nt}$, remained and were used in downstream analysis. Rarefaction curves (cf. supplementary materials) for each electrode leveled off, which indicated that the sequencing was deep enough to obtain a good coverage of the microbial diversity. The sequences were clustered into 630 operational taxonomic units (OTUs) at 3\% distance threshold. They were used in the calculations of diversity indexes for each biocathode (Table 1).

The numbers of OTUs identified ranged from 162 for electrode 5 to 329 for electrode 1 . The chao- 1 estimated total numbers of OTUs range from 190 for electrode 5 to 413 for electrode 1 [36]. However, as pointed by Haegeman et al., the true richness remains difficult to ascertain when considering only the raw number of OTUs [37]. A better representation of the real biodiversity is reflected by the Shannon (denoted H) and Simpson 


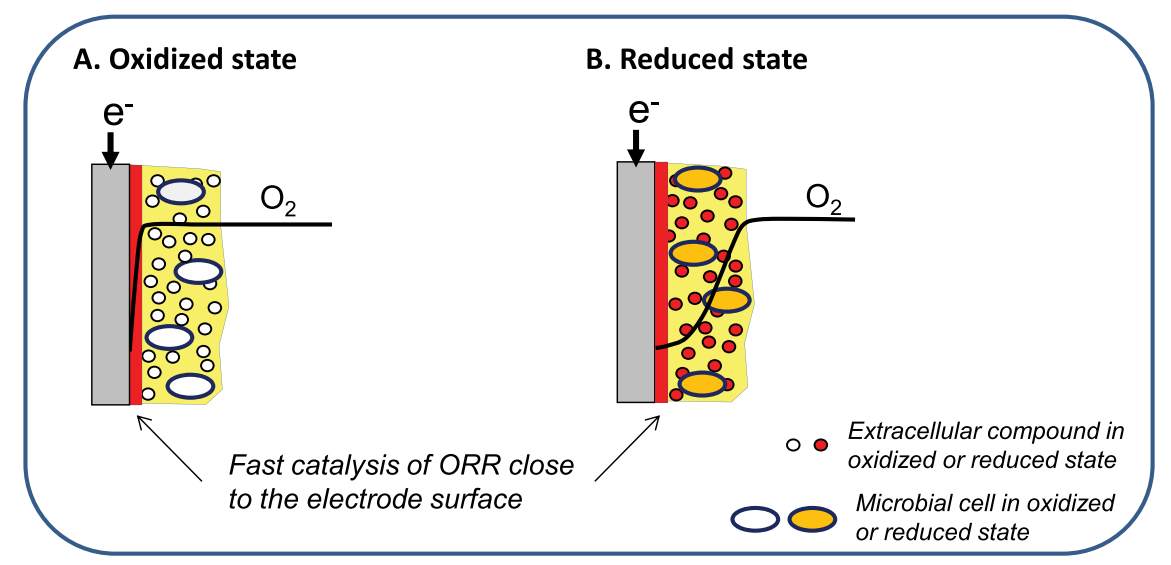

Scheme 2. Biocathode in oxidized (A) and reduced (B) states. In both cases oxygen reduction is efficiently catalyzed on the surface of, or close to, the electrode surface. The biofilm volume that is not in close vicinity to the electrode contains redox compounds (extracellular molecules or cells themselves) that undergo slow electron transfer with the electrode. Oxygen penetrates deeply into the oxidized biocathode, resulting in a high oxygen flow on the electrode surface (flow is proportional to the concentration gradient near the electrode surface). In contrast, oxygen reacts with the reduced species contained in the reduced biocathode and only a low flow reaches the electrode surface.

indexes presented in Table 1 . Two of the six cathodes had a relatively low Simpson index ( 0.92 for electrodes 2 and 6 ) while the other presented higher indexes $(0.96-0.97)$. This was congruent with the measure of Shannon indexes: $\mathrm{H} 2<\mathrm{H} 6<\mathrm{H} 3<\mathrm{H} 5<\mathrm{H} 4<\mathrm{H} 1$. Electrode 1 displayed the highest indexes, which meant that the bacterial population found on this electrode was highly diverse. Its lower performance would thus partly be explained by the failure of the electroactive bacteria in imposing on other species. In comparison, Shannon indexes measured by Xia et al. ranged from 0.67 to 1.9 [11], so Shannon indexes calculated here (between 4.99 and 6.54) were way higher. This was expected as pyrosequencing allows much deeper sequencing than clone libraries. The diversities obtained here are indeed comparable with diversities found using similar sequencing techniques on other oxygen reducing biocathodes [16-18].

The OTUs were classified using the RDP classifier and the total frequency for each given phylogenetic group was calculated [27]. Structures of the bacterial communities at the class level and major genera identified on the different electrodes are summed in supplementary materials (Fig. S2 and sup mat Table 1).
Results at the phylum level are illustrated by the DPCoA analysis (Fig. 3). The method separated the taxa in three main groups: the bottom group of Deinococcus-Thermus and Gemmatimonadetes, the upper-left group of Proteobacteria and the upper-right group of Firmicutes and Rf3 candidate division. The biofilm samples E1-6 from electrodes 1-6 were separated along the three corresponding directions depending on the bacterial compositions of their communities. Thus E2, E3 and E4 were mainly enriched in bacteria belonging to Deinococcus-Thermus and Gemmatimonadetes, E5 appeared enriched in Firmicutes and in bacteria belonging to Rf3 candidate division and E6 were mainly enriched in Proteobacteria. On the contrary, the position of E1 in the center of the graph reflected the high diversity of its populations. These results confirmed the analysis of diversity indexes indicating that there was a stronger selection of bacterial populations on active cathodes 2-6 in comparison with cathode 1 which displayed a low current density. In addition the potential used at the beginning of the experiment influenced the taxa selected. Indeed the selection is homogeneous in the biofilms of active electrodes 2-4 polarized at $-0.2 \mathrm{~V} / \mathrm{SCE}$ (enriched in Deinococcus-Thermus and Gemmatimonadetes) while we observed

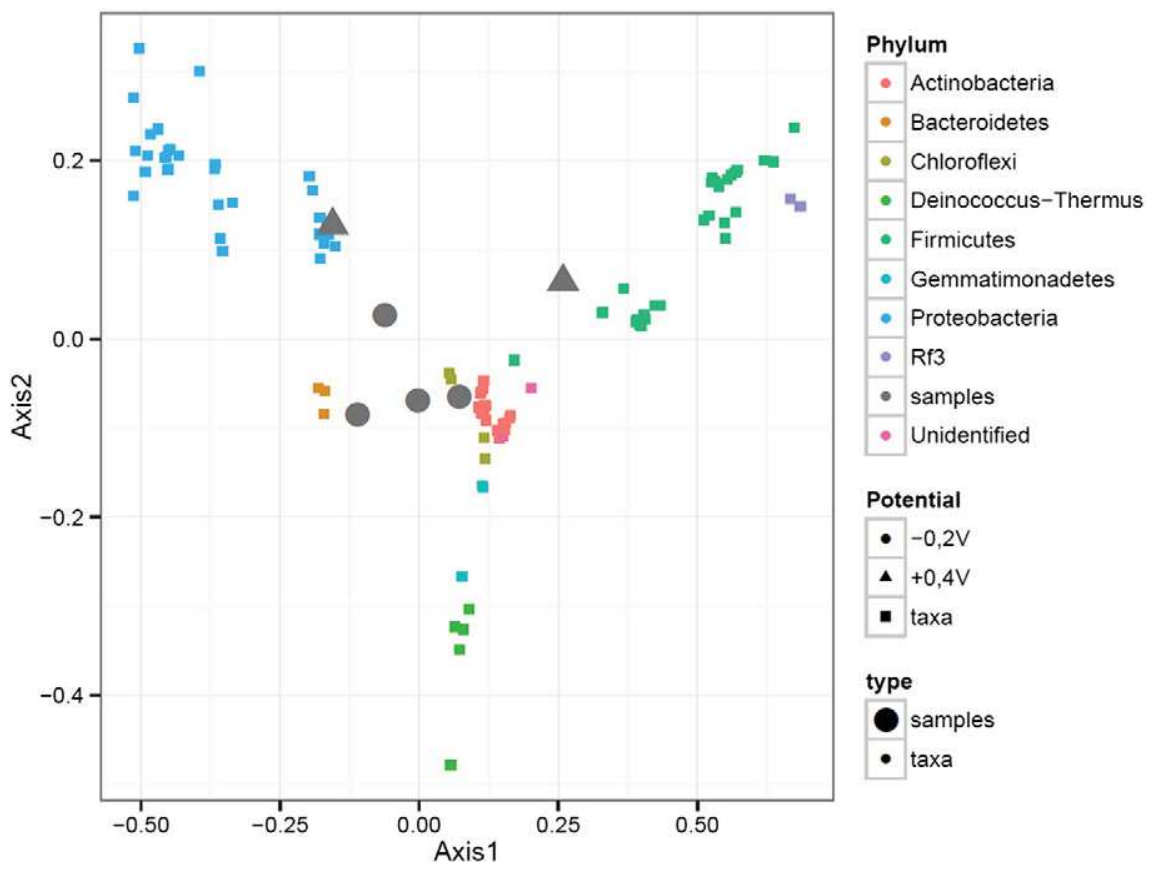

Fig. 3. DPCoA analysis at phylum level of the six electrodes populations. 
that different bacteria were selected in the biofilms of electrode first polarized at $+0.4 \mathrm{~V} / \mathrm{SCE}$ (Firmicutes and Proteobacteria respectively for E5 and E6). This was probably explained by a drift of the communities in the biofilms of electrodes 5 and 6 during their polarization at high potential, when there was no current. The communities selected in the end would then depend on the bacteria which were the first to take advantage of the electrons when the potential was switched to $-0.2 \mathrm{~V} / \mathrm{SCE}$. On the whole, these results support the suggestion already encountered in the literature that the ability to catalyze oxygen reduction in electroactive biofilms is shared by a great number of bacterium genera and species [38].

At the genera level, the most significant components of the community (relative abundance $>10 \%$ in at least one experiment) were Truepera (Deinococci), Alcaligenes ( $\beta$-Proteobacteria), Thauera ( $\beta$-Proteobacteria), Candidatus microthrix (Acidimicrobiia), Pseudomonas ( $\gamma$-Proteobacteria) or member of unclassified genera belonging to orders Xanthomonadales ( $\gamma$-Proteobacteria), Gemmatimonadales (Gemmatimonadetes) and Bacillales (Bacilli). These genera are common bacteria from activated sludge, among them, Pseudomonas aeruginosa [39], Alcaligenes faecalis [40] and different species of Bacillus [40,41] are well-known electroactive bacteria. Pseudomonas aeruginosa, in particular, is known to be able to catalyze oxygen reduction when adhering to a cathode [39]. The higher presence of Pseudomonas (10.9\%) on electrode 3 may thus explain why this electrode displayed better performances than electrode 2 and 4 (cf. supp mat Table 1). Deinococci, Rhodocyclales (Thauera), Xanthomonadales and Gemmatimonadales have also been identified in previous studies on biocathodes $[16,18]$. However the dominance of Deinococci observed on electrodes 2 to 4 was unexpected.

Indeed Deinococci lineages identified in environmental samples generally constitute a small fraction of the microbial communities [42]. This class of bacteria is mainly known for its extremely radiation resistant members and for some species used in biotechnology for their efficient DNA reparation system [43-45], but has not been proved to be electroactive yet. The classifier identified more precisely the Deinococci found here as belonging to genus Truepera, however their representative sequences appeared to be only 90\% identical to the sequence of Truepera radiovictrix in RefSeq (NR_074381 in http://www.ncbi.nlm. nih.gov/refseq/). The genus attribution was thus incorrect, the classifier probably suffering from the lack of diversity in reference sequences for the group. A maximum-likelihood phylogenetic tree that included several sequences of type species from the phylum Deinococcus-Thermus, together with sequences from uncultured bacteria closely related to our OTUs was then reconstructed and is presented in supplementary material (Fig. S3). It demonstrates that the lineages found into our biofilms form a distinct line of descent, sister to Truepera (Fig. S3). The uncultured bacteria whose sequences are closely related to our representative sequences were found in environments similar to our inoculum original environment (leachate, composting soil, tannery sludge), but were always minor components of their respective bacterial communities. Truepera radiovictrix is notably of special interest, not only because of its isolated phylogenetic location in the order Deinococcales, but also because of its ability to grow under multiple extreme conditions in alkaline, moderately saline, and high temperature habitats. As they are able to grow under such extreme conditions (alkaline, moderately saline and high temperature) Truepera radiovictrix affiliated lineages may thus be of special interest for OR biocathodes. Indeed, strains of Truepera radiovictrix were able to grow at $\mathrm{pH} 11.2$ [46]: it was thus fully consistent with the alkaline $\mathrm{pH}$, which the solution evolved to.

\section{Conclusions}

The current densities obtained here $(0.21 \pm 0.03$ and $0.12 \pm$ $0.01 \mathrm{~A} \mathrm{~m}^{-2}$ with the biocathodes formed at -0.2 and $0.4 \mathrm{~V} / \mathrm{SCE}$, respectively) were high considering the alkaline $\mathrm{pH}$ of $10.3 \pm 0.3$. The absence of phosphate buffer and $\mathrm{pH}$ control allowed the microbial populations to adapt to alkaline $\mathrm{pH}$ and develop efficient OR electrochemical properties at this $\mathrm{pH}$.

All biocathodes exhibited a high bacterial diversity but a clear difference in selective conditions was experienced. The electrodes polarized at $+0.4 \mathrm{~V} / \mathrm{SCE}$ displayed populations dissimilar from one another (dominated by Firmicutes or Proteobacteria), while electrodes polarized at $-0.2 \mathrm{~V} / \mathrm{SCE}$ displayed closer populations, as clearly shown by the DPCoA analysis. The three most efficient biocathodes had bacterial communities with high similarities between them, enriched in Deinococcus-Thermus and Gemmatimonadetes, and the less large diversity. The deviant biocathode also obtained at $-0.2 \mathrm{~V} / \mathrm{SCE}$, which gave the worst OR performance, did not exhibit similar microbial enrichment but had the more diverse bacterial community.

OR efficiency was consequently related to a given composition of the microbial community. The applied potential used to form the biocathodes is an essential parameter to act on microbial selection. Nevertheless, this is not the absolute guarantee to control the microbial enrichment; some deficiency in microbial selection can explain the deviant results that are commonly observed when forming OR biocathodes. Finally, this work also described an unexpected way for selecting Deinococci, which may have a large interest in biotechnology.

\section{Acknowledgments}

This work has benefited from a support of the French state managed by Agence Nationale de la Recherche, within the framework of the French Investissement d'Avenir program, project number ANR-10BTBR-02. The authors thank Dr Laure Renvoisé and Suez Environnement for supplying the aerobic sludge used in the experiments.

\section{Appendix A. Supplementary data}

Supplementary data to this article can be found online at http://dx. doi.org/10.1016/j.bioelechem.2014.11.006.

\section{References}

[1] B. Erable, D. Feron, A. Bergel, Microbial catalysis of the oxygen reduction reaction for microbial fuel cells: a review, Chemsuschem 5 (2012) 975-987, http://dx.doi.org/ $10.1002 / \operatorname{cssc} 201100836$

[2] B. Erable, I. Vandecandelaere, M. Faimali, M.-L. Delia, L. Etcheverry, P. Vandamme, et al., Marine aerobic biofilm as biocathode catalyst, Bioelectrochemistry 78 (2010) 51-56, http://dx.doi.org/10.1016/j.bioelechem.2009.06.006.

[3] I. Vandecandelaere, O. Nercessian, M. Faimali, E. Segaert, A. Mollica, W. Achouak et al., Bacterial diversity of the cultivable fraction of a marine electroactive biofilm, Bioelectrochemistry 78 (2010) 62-66, http://dx.doi.org/10.1016/j.bioelechem. 2009.07.004.

[4] Z. Chen, Y. Huang, J. Liang, F. Zhao, Y. Zhu, A novel sediment microbial fuel cell with a biocathode in the rice rhizosphere, Bioresour. Technol. 108 (2012) 55-59, http://dx. doi.org/10.1016/j.biortech.2011.10.040.

[5] J. Cha, S. Choi, H. Yu, H. Kim, C. Kim, Directly applicable microbial fuel cells in aeration tank for wastewater treatment, Bioelectrochemistry 78 (2010) 72-79, http:// dx.doi.org/10.1016/j.bioelechem.2009.07.009.

[6] P. Clauwaert, D. Van der Ha, N. Boon, K. Verbeken, M. Verhaege, K. Rabaey, et al., Open air biocathode enables effective electricity generation with microbial fuel cells, Environ. Sci. Technol. 41 (2007) 7564-7569, http://dx.doi.org/10.1021/es0709831.

[7] P. Liang, M. Fan, X. Cao, X. Huang, Evaluation of applied cathode potential to enhance biocathode in microbial fuel cells, J. Chem. Technol. Biotechnol. 84 (2009) 794-799, http://dx.doi.org/10.1002/jctb. 2114.

[8] D.P.B.T.B. Strik, M. Picot, C.J.N. Buisman, F. Barriere, $\mathrm{pH}$ and temperature determine performance of oxygen reducing biocathodes, Electroanalysis 25 (2013) 652-655.

[9] A. Ter Heijne, O. Schaetzle, S. Gimenez, F. Fabregat-Santiago, J. Bisquert, D.P.B.T.B. Strik, et al., Identifying charge and mass transfer resistances of an oxygen reducing biocathode, Energy Environ. Sci. 4 (2011) 5035-5043, http://dx.doi.org/10.1039/ c1ee02131a.

[10] A. Ter Heijne, D.P.B.T.B. Strik, H.V.M. Hamelers, C.J.N. Buisman, Cathode potential and mass transfer determine performance of oxygen reducing biocathodes in microbial fuel cells, Environ. Sci. Technol. 44 (2010) 7151-7156, http://dx.doi.org/10. 1021/es100950t.

[11] X. Xia, Y. Sun, P. Liang, X. Huang, Long-term effect of set potential on biocathodes in microbial fuel cells: electrochemical and phylogenetic characterization, Bioresour. Technol. 120 (2012) 26-33, http://dx.doi.org/10.1016/j.biortech.2012.06.017. 
[12] G.-W. Chen, S.-J. Choi, J.-H. Cha, T.-H. Lee, C.-W. Kim, Microbial community dynamics and electron transfer of a biocathode in microbial fuel cells, Korean J. Chem. Eng. 27 (2010) 1513-1520

[13] K. Rabaey, S.T. Read, P. Clauwaert, S. Freguia, P.L. Bond, L.L. Blackall, et al., Cathodic oxygen reduction catalyzed by bacteria in microbial fuel cells, ISME J. 2 (2008) 519-527, http://dx.doi.org/10.1038/ismej.2008.1.

[14] Y. Sun, J. Wei, P. Liang, X. Huang, Microbial community analysis in biocathode microbial fuel cells packed with different materials, AMB Express 2 (2012) 21, http://dx. doi.org/10.1186/2191-0855-2-21.

[15] K.C. Wrighton, B. Virdis, P. Clauwaert, S.T. Read, R.A. Daly, N. Boon, et al., Bacterial community structure corresponds to performance during cathodic nitrate reduction, ISME J. 4 (2010) 1443-1455, http://dx.doi.org/10.1038/ismej.2010.66.

[16] R.R. Sayess, P.E. Saikaly, M. El-Fadel, D. Li, L. Semerjian, Reactor performance in terms of COD and nitrogen removal and bacterial community structure of a threestage rotating bioelectrochemical contactor, Water Res. 47 (2013) 881-894, http://dx.doi.org/10.1016/j.watres.2012.11.023.

[17] H. Wang, S.C. Jiang, Y. Wang, B. Xiao, Substrate removal and electricity generation in a membrane-less microbial fuel cell for biological treatment of wastewater, Bioresour. Technol. 138 (2013) 109-116, http://dx.doi.org/10.1016/j.biortech.2013. 03.172.

[18] Z. Wang, Y. Zheng, Y. Xiao, S. Wu, Y. Wu, Z. Yang, et al., Analysis of oxygen reduction and microbial community of air-diffusion biocathode in microbial fuel cells, Bioresour. Technol. 144 (2013) 74-79, http://dx.doi.org/10.1016/j.biortech.2013. 06.093.

[19] M. Rimboud, D. Pocaznoi, B. Erable, A. Bergel, Electroanalysis of microbial anodes for bioelectrochemical systems: basics, progress and perspectives, Phys. Chem. Chem. Phys. PCCP 16 (2014) 16349-16366, http://dx.doi.org/10.1039/c4cp01698j.

[20] B.E. Logan, Essential data and techniques for conducting microbial fuel cell and other types of bioelectrochemical system experiments, Chemsuschem 5 (2012) 988-994, http://dx.doi.org/10.1002/cssc.201100604.

[21] D. Bougard, N. Bernet, D. Cheneby, J.P. Delgenes, Nitrification of a high-strength wastewater in an inverse turbulent bed reactor: effect of temperature on nitrite accumulation, Process Biochem. 41 (2006) 106-113, http://dx.doi.org/10.1016/j. procbio.2005.03.064.

[22] J.G. Caporaso, J. Kuczynski, J. Stombaugh, K. Bittinger, F.D. Bushman, E.K. Costello, et al., QIIME allows analysis of high-throughput community sequencing data, Nat. Methods 7 (2010) 335-336, http://dx.doi.org/10.1038/nmeth.f.303.

[23] J.G. Caporaso, K. Bittinger, F.D. Bushman, T.Z. DeSantis, G.L. Andersen, R. Knight, PyNAST: a flexible tool for aligning sequences to a template alignment, Bioinformatics 26 (2010) 266-267, http://dx.doi.org/10.1093/bioinformatics/btp636.

[24] C. Quast, E. Pruesse, P. Yilmaz, J. Gerken, T. Schweer, P. Yarza, et al., The SILVA ribosomal RNA gene database project: improved data processing and web-based tools, Nucleic Acids Res. 41 (2013) D590-D596, http://dx.doi.org/10.1093/nar/gks1219.

[25] B.J. Haas, D. Gevers, A.M. Earl, M. Feldgarden, D.V. Ward, G. Giannoukos, et al., Chimeric 16S rRNA sequence formation and detection in Sanger and 454-pyrosequenced PCR amplicons, Genome Res. 21 (2011) 494-504, http://dx.doi.org/10.1101/gr.112730.110.

[26] R.C. Edgar, Search and clustering orders of magnitude faster than BLAST, Bioinformatics 26 (2010) 2460-2461, http://dx.doi.org/10.1093/bioinformatics/btq461.

[27] J.R. Cole, Q. Wang, E. Cardenas, J. Fish, B. Chai, R.J. Farris, et al., The ribosomal database project: improved alignments and new tools for rrna analysis, Nucleic Acids Res. 37 (2009) D141-D145, http://dx.doi.org/10.1093/nar/gkn879.

[28] P.J. McMurdie, S. Holmes, phyloseq: an $r$ package for reproducible interactive analysis and graphics of microbiome census data, PLoS One 8 (2013) e61217, http://dx. doi.org/10.1371/journal.pone.0061217.

[29] M.N. Price, P.S. Dehal, A.P. Arkin, FastTree: computing large minimum evolution trees with profiles instead of a distance matrix, Mol. Biol. Evol. 26 (2009) 1641-1650, http://dx.doi.org/10.1093/molbev/msp077.
[30] W. Ludwig, O. Strunk, R. Westram, L. Richter, H. Meier, Yadhukumar, et al., ARB: a software environment for sequence data, Nucleic Acids Res. 32 (2004) 1363-1371, http:// dx.doi.org/10.1093/nar/gkh293.

[31] A. Criscuolo, S. Gribaldo, BMGE (Block mapping and gathering with entropy): a new software for selection of phylogenetic informative regions from multiple sequence alignments, BMC Evol. Biol. 10 (2010) 210, http://dx.doi.org/10.1186/1471-214810-210.

[32] S. Guindon, O. Gascuel, A simple, fast, and accurate algorithm to estimate large phylogenies by maximum likelihood, Syst. Biol. 52 (2003) 696-704, http://dx.doi.org/ 10.1080/10635150390235520.

[33] B. Cercado, N. Byrne, M. Bertrand, D. Pocaznoi, M. Rimboud, W. Achouak, et al., Garden compost inoculum leads to microbial bioanodes with potential-independent characteristics, Bioresour. Technol. 134 (2013) 276-284.

[34] S.F. Ketep, A. Bergel, M. Bertrand, W. Achouak, E. Fourest, Lowering the applied potential during successive scratching/re-inoculation improves the performance of microbial anodes for microbial fuel cells, Bioresour. Technol. 127 (2013) 448-455.

[35] T.H.J.A. Sleutels, H.V.M. Hamelers, R.A. Rozendal, C.J.N. Buisman, Ion transport resistance in microbial electrolysis cells with anion and cation exchange membranes, Int. J. Hydrog. Energy 34 (2009) 3612-3620, http://dx.doi.org/10.1016/j.ijhydene.2009. 03.004.

[36] A. Chao, Nonparametric-estimation of the number of classes in a population, Scand J. Stat. 11 (1984) 265-270.

[37] B. Haegeman, J. Hamelin, J. Moriarty, P. Neal, J. Dushoff, J.S. Weitz, Robust estimation of microbial diversity in theory and in practice, ISME J. 7 (2013) 1092-1101, http:// dx.doi.org/10.1038/ismej.2013.10.

[38] A. Cournet, M.-L. Delia, A. Bergel, C. Roques, M. Berge, Electrochemical reduction of oxygen catalyzed by a wide range of bacteria including Gram-positive, Electrochem. Commun. 12 (2010) 505-508, http://dx.doi.org/10.1016/j.elecom.2010.01.026.

[39] A. Cournet, M. Berge, C. Roques, A. Bergel, M.-L. Delia, Electrochemical reduction of oxygen catalyzed by Pseudomonas aeruginosa, Electrochim. Acta 55 (2010) 4902-4908, http://dx.doi.org/10.1016/j.electacta.2010.03.085.

[40] G. Zhang, Q. Zhao, Y. Jiao, K. Wang, D.-J. Lee, N. Ren, Efficient electricity generation from sewage sludge using biocathode microbial fuel cell, Water Res. 46 (2012) 43-52, http://dx.doi.org/10.1016/j.watres.2011.10.036.

[41] V.R. Nimje, C.-Y. Chen, C.-C. Chen, J.-S. Jean, A.S. Reddy, C.-W. Fan, et al., Stable and high energy generation by a strain of Bacillus subtilis in a microbial fuel cell, J. Power Sources 190 (2009) 258-263, http://dx.doi.org/10.1016/j.jpowsour.2009.01.019.

[42] R. Chaturvedi, G. Archana, Novel 165 rRNA based PCR method targeting Deinococcus spp. and its application to assess the diversity of deinococcal populations in environmental samples, J. Microbiol. Methods 90 (2012) 197-205, http://dx.doi.org/10. 1016/j.mimet.2012.05.005.

[43] A. Krisko, M. Radman, Biology of extreme radiation resistance: the way of Deinococcus radiodurans, Cold Spring Harb. Perspect. Biol. 5 (2013), http://dx.doi. org/10.1101/cshperspect.a012765.

[44] D. Slade, M. Radman, Oxidative stress resistance in Deinococcus radiodurans, Microbiol. Mol. Biol. Rev. 75 (2011), http://dx.doi.org/10.1128/MMBR. 00015-10 (133-+).

[45] D. Slade, A.B. Lindner, G. Paul, M. Radman, Recombination and replication in DNA repair of heavily irradiated Deinococcus radiodurans, Cell 136 (2009) 1044-1055, http://dx.doi.org/10.1016/j.cell.2009.01.018.

[46] L. Albuquerque, C. Simoes, M.F. Nobre, N.M. Pino, J.R. Battista, M.T. Silva, et al., Truepera radiovictrix gen. nov., sp nov., a new radiation resistant species and the proposal of Trueperaceae fam. nov. FEMS Microbiol. Lett. 247 (2005) 161-169, http://dx.doi.org/10.1016/j.femsle.2005.05.002. 